\title{
Alterações cognitivas de idosos no contexto domiciliar e atitudes de crianças em relação à velhice*
}

\author{
COGNITIVE ALTERATIONS OF THE ELDERLY IN HOME SETTINGS AND THE \\ ATTITUDES OF CHILDREN TOWARDS AGING
}

\author{
ALTERACIONES COGNITIVAS DEL ANCIANO EN CONTEXTO DOMICILIARIO Y \\ ACTITUDES DE INFANTES EN RELACIÓN A LA VEJEZ
}

\author{
Bruna Moretti Luchesi ${ }^{1}$, Sofia Cristina lost Pavarini $^{2}$, Aline Silveira Viana ${ }^{3}$
}

\begin{abstract}
RESUMO
Crianças desenvolvem atitudes em relação à velhice desde o nascimento, influenciadas por fatores cotidianos. Objetivou-se avaliar e comparar a atitude em relação à velhice de crianças morando com idosos com e sem alterações cognitivas. Realizaram-se entrevistas domiciliares com 54 crianças de cinco USF, 25 morando com idosos com alterações cognitivas (grupo 1) e 29 com idosos sem alterações cognitivas (grupo 2). Os cuidados éticos foram observados. Aplicou-se a Escala de Atitudes em Relação à Velhice para Crianças, na qual a pontuação média foi de 1,66 pontos (grupo 1) e 1,52 (grupo 2). Um ponto representava a pontuação mais positiva e três pontos a mais negativa possível. Comparando os grupos, os domínios cognição e relacionamento social apresentaram índices significativos, indicando que crianças convivendo com idosos com alteração cognitiva têm atitudes mais negativas nestes domínios. Profissionais de saúde na atenção básica devem atentar-se às famílias multigeracionais e investir na educação das mesmas.
\end{abstract}

\section{DESCRITORES}

Idoso

Criança

Relação entre gerações

Atitude

Enfermagem familiar

\begin{abstract}
Children develop attitudes towards aging from birth and are influenced by everyday factors. The objective of this study was to evaluate attitudes towards aging of children living with elderly individuals with and without cognitive changes. Home interviews were performed with 54 children from five Family Health Units, 25 of whom lived with seniors with cognitive changes (group 1), and 29 living with seniors without cognitive changes (group 2). All ethical precautions were observed. The Scale for Children's Attitudes Towards Aging was used. The mean scores obtained were 1.66 (group 1) and 1.52 (group 2). One point represented the most positive possible score, and three points the most negative. The comparison between groups, cognition domains, and social relationships presented significant rates, showing that children living with seniors with cognitive changes have more negative attitudes in these domains. Primary healthcare professionals should pay close attention to multigenerational families and invest in their education.
\end{abstract}

DESCRIPTORS
Aged
Child
Intergenerational relations
Attitude
Family nursing

\section{RESUMEN}

Los niños desarrollan actitudes relacionadas a la vejez desde el nacimiento, influenciadas por factores cotidianos. Se objetivó evaluar y comparar la actitud relacionada a la vejez de niños viviendo con ancianos con y sin alteraciones cognitivas. Se realizaron entrevistas domiciliarias con 54 infantes de cinco USF, 25 viviendo con ancianos con alteraciones cognitivas (grupo 1) y 29 con ancianos sin alteraciones (grupo 2). Se observaron los cuidados éticos. Se aplicó Escala de Actitudes Relacionadas a la Vejez para Infantes; el puntaje promedio fue 1,66 (grupo 1) y 1,52 (grupo 2). Un punto representa el score más positivo, tres puntos, el score más negativo. Comparando los grupos, los dominios cognición y relación social presentaron índices significativos, indicando que infantes conviviendo con ancianos con alteraciones cognitivas tienen actitudes más negativas en estos dominios. Profesionales de salud en atención básica deberían alentar a las familias multigeneracionales a invertir en la educación del infante.

DESCRIPTORES
Anciano
Niño
Relaciones Intergeneracionales
Actitud
Enfermería de la familia

\footnotetext{
* Extraído da dissertação "Crianças que convivem com idosos: atitudes em relação à velhice e percepção sobre demência", Universidade Federal de São Carlos, 2011. ${ }^{1}$ Enfermeira. Mestranda do Programa de Pós-Graduação em Enfermagem da Universidade Federal de São Carlos. Membro do Grupo de Pesquisa Saúde e Envelhecimento/CNPq. São Carlos, SP, Brasil. bruna_luchesi@yahoo.com.br ${ }^{2}$ Enfermeira. Doutora em Educação pela Universidade Estadual de Campinas. Professora Associada do Departamento de Enfermagem da Universidade Federal de São Carlos. Líder do Grupo de Pesquisa Saúde e Envelhecimento/CNPq. São Carlos, SP, Brasil. sofia@ufscar.br ${ }^{3}$ Graduanda em Gerontologia da Universidade Federal de São Carlos. Membro do Grupo de Pesquisa Saúde e Envelhecimento/CNPq. São Carlos, SP, Brasil. aline_geronto@hotmail.com
} 


\section{INTRODUÇÃO}

No Brasil, tradicionalmente e legalmente, quem é responsável pelo cuidado de um idoso dependente é a família. Segundo o artigo 230 da Constituição Federal Brasileira,

a família, a sociedade e o Estado têm o dever de amparar as pessoas idosas, assegurando sua participação na comunidade, defendendo sua dignidade e bem-estar e garantindo-Ihes o direito à vida(1).

As famílias envelhecem junto com os idosos, já que aumenta o número de famílias que têm um idoso residindo na mesma casa. Além disso, pode ocorrer a verticalização familiar, ou seja, a convivência de várias gerações ao mesmo tempo, podendo indicar co-residência ou não(2).

Existem dois tipos de famílias que possuem idosos na sua configuração: as famílias de idosos, em que o idoso é o chefe ou cônjuge e as famílias com idosos, em que o idoso é parente do chefe. O tamanho médio das famílias de idosos, no ano de 2000 era de 3,3 pessoas e das famílias com idosos de cinco pessoas. Os domicílios de idosos são os que mais crescem, o que pode indicar um aumento da dependência de outros familiares em relação ao idoso chefe ${ }^{(2-3)}$.

A configuração familiar predominante no Brasil ainda é o casal de idosos com fiIhos, ou seja, o arranjo bigeracional, representado por $43,3 \%$ dos domicílios de idosos. Esta configuração apesar de predominante está em declínio, e crescem as configurações que apresentam idosos morando sós, casal sem filhos e ainda os domicílios com três gerações ${ }^{(2)}$.

Nas famílias de idosos, no ano 2000, 14\% dos membros eram netos do idoso e nas famílias com idosos os netos foram representados por 2,2\%. Em média $12 \%$ das famílias que contém idosos em sua configuração são netos, e a maioria deles tem entre zero e 14 anos (72,5\% dos netos das famílias de idosos e $94,6 \%$ das famílias com idosos) $)^{(2)}$.

O fato de a criança conviver com um idoso, independente de ser avô/ó, pai/mãe ou possuir outro vínculo, mesmo não sendo familiar, pode influenciar a atitude da criança em relação ao idoso e temas relacionados ao envelhecimento.

(...) atitudes são predisposições aprendidas e relativamente estáveis para responder ante um objeto e compreendem três componentes: cognitivo, emocional e tendência à ação. O componente cognitivo inclui as crenças avaliativas sobre um dado objeto e, em parte, refletem normas sociais. O componente emocional refere-se aos sentimentos experimentados pelo indivíduo em relação ao objeto. Tendência à ação significa a disposição do indivíduo a entrar em interação com o objeto(4).
As atitudes avaliam sinteticamente um objeto, são atributos bipolares, não são observáveis, mas podem ser inferidas e avaliadas. Além disso, têm um papel orientador, integrador e controlador no comportamento das pessoas $^{(5-7)}$. Decorrem de processos comuns de aprendizagem e apesar de serem relativamente estáveis, são passíveis de mudanças, sendo a educação uma ferramenta central em qualquer tentativa de mudança de atitude ${ }^{(6,8)}$.

Elas têm duas dimensões, a direção, expressa em atributos antagônicos como positivo-negativo e a intensidade, expressa em diferentes graus ${ }^{(9)}$. Podem representar avaliações sobre diversos objetos e o interesse em se pesquisar atitudes iniciou-se ao avaliar em diversas nações o impacto político do autoritarismo e intolerância. Através destas avaliações, foi possível esclarecer alguns fenômenos de massa e aperfeiçoar técnicas estatísticas, o que fez com que outros objetos sociais passassem a ser investigados, entre eles a velhice ${ }^{(5)}$.

Os primeiros estudos sobre atitudes em relação à velhice são datados de meados dos anos 40 , porém o marco mais importante foi representado em um estudo que objetivou investigar atitudes de um grupo de 147 adultos jovens americanos em relação à velhice, através de um questionário(10).

Existem vários modos de avaliar atitudes em relação à velhice. No Brasil, uma das escalas mais usadas foi desenvolvida e é chamada Escala Neri. Essa é composta por 40 pares de adjetivos bipolares, com sete níveis de intensidade para cada par de adjetivos e foi aplicada a uma amostra de 4300 brasileiros não idosos ${ }^{(11)}$. Outros estudos foram feitos e a escala inicial foi refeita, passando a ter 30 pares de adjetivos e cinco níveis de intensidade ${ }^{(12)}$.

A Escala Neri ${ }^{(11-12)}$ é dividida em quatro domínios: cognição, agência, relacionamento social e persona. $O$ domínio cognição refere-se à capacidade de processamento da informação e da solução de problemas, com reflexos sobre adaptação social; agência se refere à autonomia e instrumentalidade para realização de ações; relacionamento social a aspectos afetivo-emocionais, refletindo na interação social e persona a rótulos sociais comumente usados para designar ou discriminar idosos ${ }^{(8,11,13)}$.

$\mathrm{Na}$ avaliação de atitudes em relação à velhice em crianças, são poucos os dados da literatura. Internacionalmente esses estudos datam da década de 70, porém, no Brasil os mesmos são recentes. O estudo com crianças é importante, já que muitas atitudes significativas são formadas muito cedo na vida e podem persistir ${ }^{(14)}$.

No Brasil, optou-se por elaborar uma escala nos moldes do diferencial semântico, baseada na Escala Neri inicial $^{(11-12)}$ e adaptá-la para crianças em idade escolar ${ }^{(15)}$. A versão final foi denominada Escala Todaro para Avaliação 
de Atitudes de Crianças em Relação a Idosos e consta de 14 itens bipolares, com três níveis de intensidade, a serem respondidos pelas crianças em que elas devem escolher a melhor alternativa para Os idosos são:(15). Os itens são divididos nos quatro domínios citados anteriormente ${ }^{(11-12)}$ : cognição, agência, relacionamento social e persona. A consistência interna da escala foi testada e considerada satisfatória para crianças de sete a dez anos.

As atitudes em relação à velhice decorrem de processos comuns de aprendizagem, portanto o contexto de vida da pessoa pode influenciá-las. Um dos contextos que crianças comumente vivenciam atualmente é a presença de idosos na família, que podem possuir alterações cognitivas. Diante disso, a pergunta de pesquisa foi: a presença de idosos com alterações cognitivas na casa de crianças pode influenciar a atitude em relação à velhice das mesmas?

Considerando que com o aumento no número de idosos aumenta a proporção de pessoas com alterações cognitivas na população e as crianças convivem com estas, este trabalho teve por objetivo avaliar e comparar a atitude em relação à velhice de crianças que moram com idosos com e sem alterações cognitivas.

\section{MÉTODO}

Trata-se de um estudo transversal, descritivo e quantitativo, realizado em um município de médio porte no interior paulista.

Foram sujeitos desta pesquisa crianças de sete a dez anos, cadastradas em cinco diferentes Unidades de Saúde da Família (USF), que moravam com pelo menos um idoso (maior de 60 anos) na mesma casa. A seleção foi feita através da ficha de cadastramento das famílias nas USF, em que consta o nome e idade de todas as pessoas que moram na casa.

Todas as crianças com as características citadas ( $n=103$ ) foram visitadas e excluiu-se as que não se encontraram nas suas casas após duas visitas em períodos alternados ( $n=21$ ), as que já tinham se mudado da residência ou sua casa não pertencia mais à área de cobertura do PSF $(n=27)$ e também no caso de falecimento do idoso $(n=1)$, chegando a um número final de 54 crianças. Também foi entrevistado o idoso que morava com estas crianças $(n=46)$ para que as crianças pudessem ser dividas em dois grupos: grupo 1 (crianças que moram com idosos com alterações cognitivas) e grupo 2 (crianças que moram com idosos sem alterações cognitivas).

Os cuidados éticos que regem pesquisas com seres humanos foram observados, segundo a Resolução 196/96. O projeto foi aprovado pelo Comitê de Ética em Pesquisa da Universidade (Parecer no 486/2008) e a coleta de dados teve inicio após a leitura e assinatura do Termo de Consentimentos Livre e Esclarecido pelos responsáveis das crianças e pelos idosos.
As entrevistas foram domiciliares e previamente agendadas de acordo com disponibilidade da criança, de seus pais ou responsáveis e dos idosos que moravam com as mesmas. A coleta ocorreu de junho à agosto de 2009 e compreendeu duas partes, realizadas no mesmo dia, uma após a outra.

\section{Parte I - Entrevista com o idoso}

- Aplicação de questionário sociodemográfico contendo nome, sexo, idade, escolaridade, religião, cor e plano de saúde.

- Aplicação do Mini-Exame do Estado Mental (MEEM), escolhido por ser um dos instrumentos mais usados no mundo para rastreamento de déficit cognitivo. Sinaliza se é provável que haja alguma alteração cognitiva e em que área ocorre ${ }^{(16-17)}$. As notas de corte do instrumento seguiram recomendações do Departamento Científico de Neurologia Cognitiva e do Envelhecimento da Academia Brasileira de Neurologia e foram adaptadas de acordo com o grau de escolaridade do idoso. Utilizou-se: 18 pontos para analfabetos, 21 pontos para 1 a 3 anos de escolaridade, 24 pontos para 4 a 7 anos de escolaridade e 26 pontos para 8 anos ou mais. Após aplicação do MEEM era anotado em que grupo o idoso se encaixava, 1 (com alterações cognitivas) ou 2 (sem alterações cognitivas).

Quando havia mais de um idoso que residia na casa era entrevistado aquele que tivesse presente ou aquele que tivesse maior disponibilidade em responder às questões no momento da entrevista. Quando havia mais de uma criança na casa, o idoso era entrevistado uma única vez, e todas as crianças respondiam às questões, o que explica um número maior de crianças do que idosos entrevistados. No caso de mais de uma criança na mesma casa, cada entrevista era feita separadamente.

\section{Parte II - Entrevista com a criança}

- Caracterização sociodemográfica das crianças contendo nome, endereço, USF de referência, sexo, idade, escolaridade, renda familiar, número de pessoas na casa, religião, cor, plano de saúde, sexo e grau de parentesco do idoso que mora com ela e há quanto tempo mora com o idoso.

- Sensibilização das crianças em relação ao objeto que elas iriam avaliar, ou seja, em relação à velhice. Para isso foi feita uma questão inicial: Você sabe o que é idoso? Caso a criança soubesse responder era solicitado a ela que respondesse e se fosse necessário a pesquisadora corrigia algo. Caso não soubesse responder, o conceito era explicado a ela e só depois e entrevista prosseguia.

- Aplicação da Escala de Atitudes em Relação à VeIhice para Crianças ${ }^{(15)}$. Na Escala Todaro, os itens cujos pólos positivos não estavam localizados na posição correspondente a UM ponto foram recodificados para ficar nesta posição. 
Os dados quantitativos foram tabulados, interpretados e analisados de acordo com estatísticas descritivas - média, desvio padrão (dp), frequência - e correlacionais. Foram utilizados testes estatísticos não-paramétricos aplicados pelo programa SPSS para Windows. Para todos os testes foi adotado o nível de significância de $5 \%$, ou seja, $p<0,05$.

\section{RESULTADOS}

Dos 46 idosos do estudo, 63\% eram mulheres e $37 \%$ homens. A faixa etária que mais prevaleceu foi a de 60-64 anos (43,5\%), sendo a média de 67,04 anos (dp=6,08). Em relação à escolaridade, $95,6 \%$ dos idosos ou eram analfabetos $(34,8 \%)$ ou tinham iniciado o ensino fundamental, porém sem concluí-lo $(60,8 \%)$. A religião católica foi predominante em $78,2 \%$ dos casos, seguida pela evangélica $(10,9 \%)$.

Em relação à cor, 60,9\% dos idosos se autodeclararam brancos, $21,7 \%$ pardos e $17,4 \%$ negros. Dos idosos, $6,5 \%$ possuíam plano de saúde.

O MEEM foi aplicado em 45 dos 46 idosos visitados. Um idoso não respondeu ao teste, pois já possuía diagnóstico de demência comprovado por médico especialista e possuía problemas de compreensão decorrentes de sequelas de outras doenças. A criança que morava com este idoso foi incluída no grupo 1 , ou seja, de crianças que moram com idosos com alterações cognitivas, já que devido ao diagnóstico de demência, o idoso foi considerado como portador de alterações cognitivas.

$\mathrm{Na}$ aplicação do MEEM, obteve-se $39,1 \%$ dos idosos com nota abaixo da nota de corte, $58,7 \%$ acima e um idoso não realizou o teste (2,2\%). A pontuação média foi 20,4 pontos $(d p=5,55)$.

Dos idosos com alteração cognitiva $(n=18), 61 \%$ eram do sexo feminino e $39 \%$ masculino, a maioria com idade entre $60-64$ anos (37\%) e era analfabeto (53\%) ou com ensino fundamental incompleto (47\%).
Já em relação às 54 crianças entrevistadas, a maioria é do sexo masculino (57\%). As idades mais apresentadas pelas crianças foram nove $(29,63 \%)$ e dez $(27,78 \%)$ anos. O número de crianças frequentando a 4a série do ensino fundamental foi maior (42,6\%). Apenas uma criança estava na 5a série; $24 \%$ na 3ạ série; $20,4 \%$ na 2a série e $11,1 \%$ na 1 ạ série.

Quanto ao número de pessoas na casa, contando com as crianças, houve uma média de seis pessoas $(\mathrm{dp}=2,34)$, porém o número variou de duas a doze pessoas. A renda familiar variou de $1 / 2$ a 5 salários mínimos, ou seja, em média de $R \$ 260$ à $\mathrm{R} \$ 2620$ e a média salarial foi de 2,04 salários mínimos, o que corresponde a aproximadamente $\mathrm{R} \$ 1071$.

Pouco mais da metade crianças ou seus responsáveis (quando estas não sabiam ou não queriam responder a esta questão) se autodeclararam brancas (53,7\%), 27,8\% pardas e $18,5 \%$ negras. A religião das crianças foi em sua maioria católica $(64,8 \%)$, seguida por $20,4 \%$ de evangélicos, $11,1 \%$ que disseram não possuir religião e $3,7 \%$ que não quiseram informar a mesma. Nenhuma das crianças entrevistadas possuía plano de saúde.

A maioria das crianças era neta do idoso com quem morava $(85,2 \%)$, os filhos representaram $7,4 \%$, bisnetos $(3,7 \%)$ e sobrinho-netos (3,7\%). As crianças moravam com idosos de ambos os sexos em $39 \%$ dos casos, somente com idoso do sexo feminino em $37 \%$ e somente com idoso do sexo masculino em $24 \%$ dos casos. Grande parte das crianças morava com o(s) idoso(s) há mais de cinco anos (75,9\%), seguidas pelas crianças que moravam entre três e quatro anos $(11,1 \%)$, entre quatro e cinco anos $(7,4 \%)$ e menos de três anos $(5,6 \%)$.

Após aplicação do MEEM, as crianças foram distribuídas no grupo 1 ( $n=25,46,3 \%$ ) e grupo 2 ( $n=29,53,7 \%)$. A média de pontuação na Escala de Atitude das crianças do grupo 1 foi 1,66 pontos ( $d p=0,3$ ) e a das crianças do grupo $2,1,52$ pontos $(\mathrm{dp}=0,38)$, como se vê na Figura 1, onde também aparecem as médias de pontuação dos grupos para cada domínio.

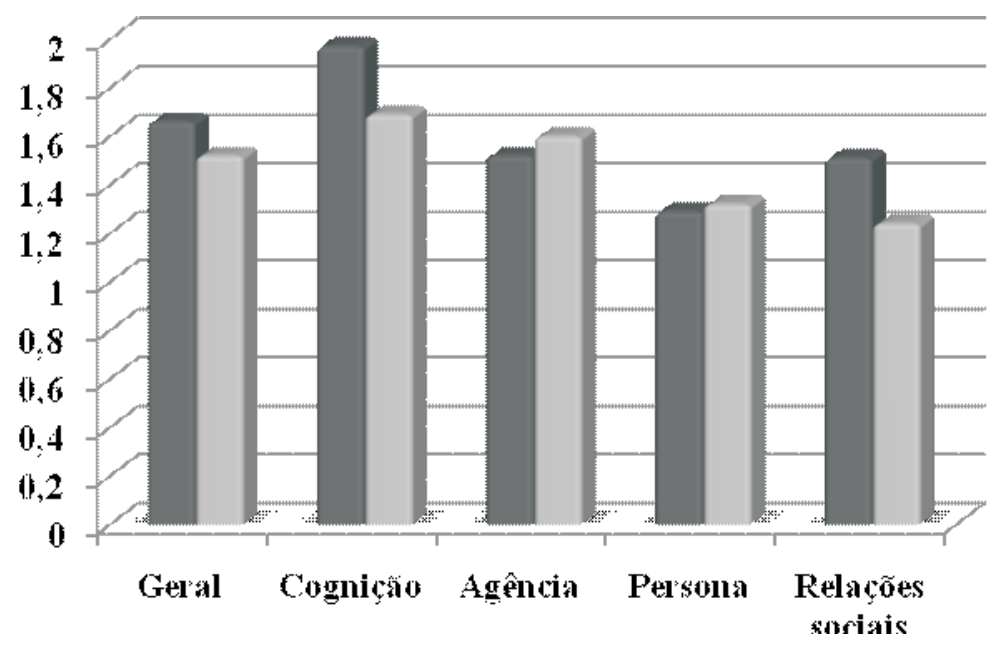

Grupo 1 - com alteracöes
cognitivas

¿arupo 2 - sem alterações cognitivas

Figura 1 - Pontuações médias para a escala e seus domínios, referentes aos grupos 1 e 2 - São Carlos, 2010

$\begin{array}{rrr}\text { Rev Esc Enferm USP } & 2012 ; 46(2): 335-41 & \text { Alterações cognitivas de idosos no contexto } \\ \text { domiciliar e atitudes de crianças em relação à velhice } \\ \text { www.ee.usp.br/reeuspl }\end{array}$


Quando os grupos 1 e 2 foram comparados através dos tes- $\quad$ te de Mann-Whitney, observou-se o demonstrado na Tabela 1.

Tabela 1 - Comparações (Mann-Whitney) entre a escala geral e seus domínios e os grupos 1 e 2 - São Carlos, 2010

\begin{tabular}{lccccc}
\hline & Escala & Cognição & Agência & Persona & $\begin{array}{c}\text { Relacionamento } \\
\text { Social }\end{array}$ \\
\hline Mann-Whitney U & 269,5 & 250 & 332 & 359 & 271,5 \\
\hline p valor & 0,053 & $0,025^{*}$ & 0,311 & 0,480 & $0,049^{*}$ \\
\hline
\end{tabular}

Nível de significância de $95 \%(p<0,05)$

Como mostra a Tabela 1, a comparação entre os grupos 1 e 2 apresentou níveis considerados significativos para o domínio cognição $(p=0,025)$ e relacionamento social $(p=0,049)$ e apresentou uma tendência de significân- cia para a pontuação geral da escala $(p=0,053)$. A Figura 2 ilustra o Rank médio, de acordo com o teste de Mann-Whitney, para a escala geral e os domínios cognição e relacionamento social.

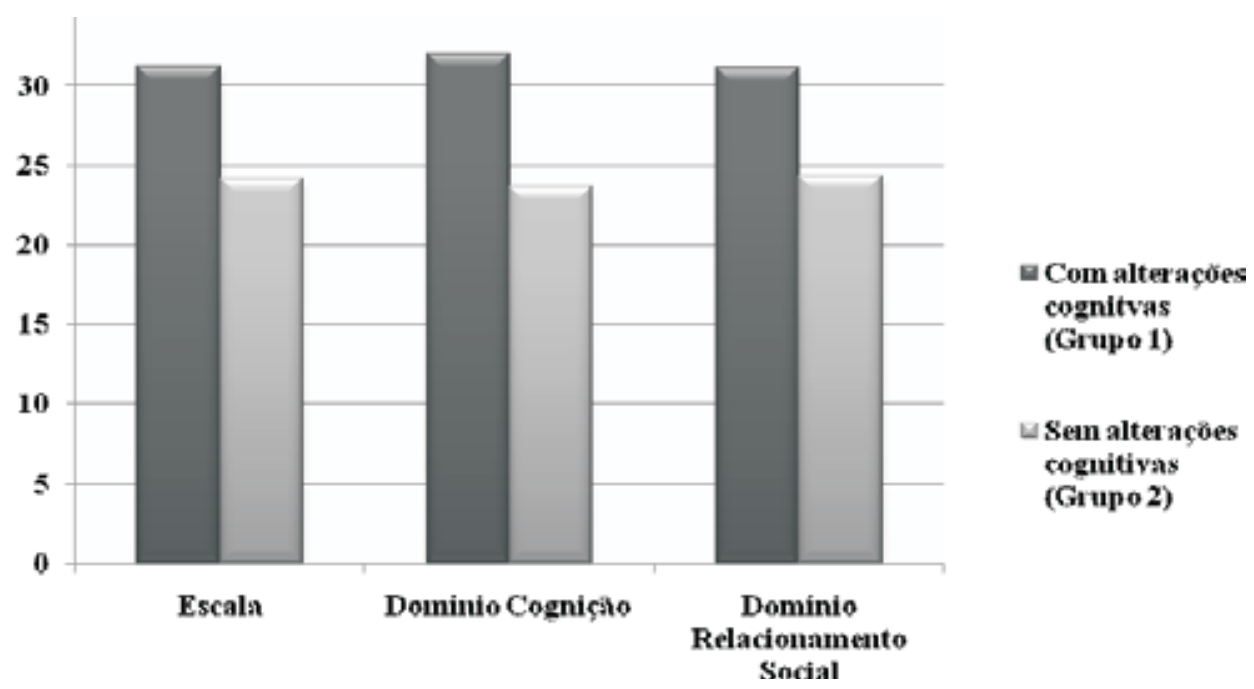

Figura 2 - Rank médio de acordo com o teste de Mann Whitney para a escala geral e os domínios cognição e relacionamento social São Carlos, 2010

As crianças que moram com idosos com alterações cognitivas possuem as médias do Rank maiores que as crianças que moram com idosos sem alterações cognitivas, o que significa que elas têm atitudes piores nos domínios cognição e relacionamento social e tendência de piores atitudes na escala geral.

\section{DISCUSSÃO}

De acordo com os resultados, foi possível traçar um perfil dos idosos que moram com crianças de sete a dez anos. Normalmente essa criança mora com idosos de ambos os sexos e quando mora somente com um idoso, este é do sexo feminino. Esses são em sua maioria idosos jovens, com pouca ou nenhuma escolaridade e a renda familiar é baixa se considerarmos que a média foi de seis pessoas na casa.

Um estudo realizado na cidade de São Paulo em 2000, com uma amostra representativa da população idosa da cidade encontrou que $32 \%$ deles tinha entre $60-64$ anos, $46 \%$ entre $65-74$ anos e $22 \%$ com 75 anos ou mais ${ }^{(18)}$. As faixas etárias que compreendem os idosos mais jovens são as que tiveram maior representação no presente estudo, inclusive encontrando números foram maiores que a literatura. Este fato pode ter ocorrido, pois as crianças do estudo tinham no máximo 10 anos de idade. Como todos os pares criança-idoso entrevistados eram da mesma família, supõe-se que para morar junto com uma criança desta idade ele seria ou pai ou avô da criança, ou seja, teria uma idade menor, o que foi confirmado.

De acordo com dados do IBGE expressos no perfil dos idosos responsáveis por domicílios no Brasil no ano 2000, $54,4 \%$ dos idosos tinha no máximo três anos de estudo ${ }^{(19)}$, o que mostra a baixa escolarização dos idosos no Brasil.

As famílias que possuíam crianças e idosos eram em média de seis pessoas. Um estudo realizado com idosos residentes em sete países da América Latina e Caribe (incluindo o Brasil) mostra que mais da metade dos idosos entrevistados mora com três ou quatro pessoas na casa e $25 \%$ com cinco ou mais pessoas. Dados somente do Brasil mostram que $37 \%$ mora com três ou quatro pessoas, $19 \%$ com cinco ou mais pessoas e somente $13 \%$ moram sozinhos $^{(18)}$. Já o perfil dos idosos responsáveis pelo domicílio no Brasil, encontrou que a média destes domicílios é de 3,2 pessoas $^{(19)}$. A Pesquisa Nacional de Amostra por Domicílio de 2008 divulgou uma média de 3,3 pessoas por domicílio ${ }^{(20)}$. 
A literatura mostra que em diferentes regiões e com sujeitos que possuem diferentes características, a média de pessoas nos domicílios em que moram idosos varia. Fatores que influenciam nesta variação vão depender da necessidade dos membros da família, do número de filhos do idoso, sexo, idade, grau de dependência, estado conjugal e até viabilidade física, financeira e condições de saúde ${ }^{(18)}$.

A maioria dos idosos era avô(ó) da criança entrevistada, o que mostra a presença de domicílios com três gerações. Porém também foram encontrados idosos pais de crianças de sete a dez anos, o que pode indicar um aumento da qualidade de vida e da vida produtiva com o advento da velhice. Grande parte das crianças morava com o idoso entrevistado há mais de cinco anos, mostrando que elas tendem a os conhecer bem, ou seja, suas atitudes podem ser influenciadas pelo comportamento dos mesmos.

Apesar entrevistados serem jovens, a porcentagem de idosos com alterações cognitivas foi bem grande. A média de pontuação foi baixa, porém isso não possui grande relevância, já que a nota que indica presença de alterações cognitivas depende da nota de corte, adaptada ao grau de escolaridade.

$\mathrm{Na}$ avaliação da atitude das crianças em relação à velhice, pode-se notar que a média de pontuação das crianças, tanto do grupo 1 como do grupo 2 foi mais próxima de um ponto, o que indica atitudes mais positivas em relação à veIhice, já que a criança podia pontuar no mínimo um ponto e no máximo três pontos. A atitude mais negativa apresentada pelos dois grupos foi no domínio cognição e a mais positiva no domínio persona, dados que corroboram com outro estudo feito no Brasil utilizando a mesma escala, que avaliou 248 crianças sendo que a maioria não morava com os avós ${ }^{(15)}$.

Apesar da atitude das crianças dos dois grupos em relação à velhice ser positiva, houve diferenças na comparação do grupo de crianças que moravam com idosos com alterações cognitivas (grupo 1) com o grupo que morava com idosos sem alterações (grupo 2).

As crianças do grupo 1 viram o fato de ser sábio, a criatividade, rapidez, atenção, segurança e clareza dos idosos (domínio cognição) com olhar mais negativo. Isso pode ter sido reflexo do idoso com quem elas moram, o qual apresenta alteração cognitiva.

No domínio relacionamento social que está ligado a aspectos afetivo-emocionais (valorização, aceitação e humor) e refletem na interação social, as crianças do grupo 1 também tiveram atitudes mais negativas. Estas crianças também tiveram a tendência de ter atitudes mais negativas na pontuação geral da escala.

Assim, crianças que convivem com idosos com alterações cognitivas, tendem a possuir atitudes mais negativas em relação à velhice no geral, mas significativamente mais negativas nos domínios cognição e relacionamento social. Os outros domínios não apresentaram índices significativos na comparação dos grupos 1 e 2 .
Devido a especificidades no processo de envelhecimento, é essencial que as crianças sejam envolvidas no processo de cuidar do idoso ${ }^{(21)}$, pois assim elas podem conhecer as qualidades e limitações que esses possuem e melhorar as atitudes em relação à eles, principalmente as crianças que moram com idosos com alterações cognitivas.

\section{CONCLUSÃO}

O presente estudo permitiu que fossem avaliadas atitudes em relação à velhice de crianças que moram com idosos com e sem alterações cognitivas. As crianças tinham de sete a dez anos e moravam, em sua maioria, com idosos de ambos os sexos, jovens, de baixa escolaridade, que eram seus avós e moravam juntos há mais de cinco anos. A renda familiar foi baixa se considerarmos que em média tinham seis pessoas na casa.

A maioria dos idosos teve pontuação acima da nota de corte adaptada para escolaridade no MEEM (58,7\%). Dos idosos que foram considerados como possuindo alterações cognitivas a maioria eram mulheres, jovens e com pouca ou nenhuma escolaridade.

Para divisão das crianças nos grupos 1 e 2 foi considerada a pontuação do idoso que mora com ela no MEEM, sendo que crianças que moravam com idosos com alterações cognitivas pertenciam ao grupo $1(46,3 \%)$ e as que moravam com idosos sem alterações cognitivas ao grupo $2(53,7 \%)$.

A pontuação média das crianças do grupo 1 foi 1,66 pontos e do grupo 2; 1,52 pontos. Quando os dois grupos foram comparados, houve diferenças significativas entre eles nos domínios cognição e relacionamento social e tendência de diferença na pontuação geral da escala.

Crianças que moram com idosos com alterações cognitivas, portanto, possuem atitudes em relação à velhice mais negativas nos domínios cognição e relacionamento social do que crianças que moram com idosos sem alterações cognitivas.

Cabe ressaltar que apesar de terem sido encontradas diferenças significativas quando foi comparada a variável pontuação na escala de atitudes das crianças e a cognição do idoso que mora com a mesma, sabe-se que outras variáveis podem ter influenciado estes resultados, como por exemplo, nos casos em que a criança morava com mais de um idoso na mesma casa. Apesar disto, as diferenças encontradas devem ser consideradas no atendimento e planejamento de ações para crianças que moram com idosos com alterações cognitivas.

Profissionais de saúde que atuam na Estratégia Saúde da Família se deparam todos os dias com as mais diversas configurações familiares. Normalmente quando a criança da família não possui alguma doença, ela não recebe merecida atenção. Os idosos que possuem doenças crônicas são frequentemente visitados e examinados, e cresce a atenção dada aos cuidadores dos mesmos. Os familiares, inclusive crianças, são muitas vezes deixados de lado na 
assistência, sendo que o cuidado recebido é mínimo. Eles devem, além de ter um plano de cuidados individual, serem inseridos no plano de cuidado dos idosos, para que entendam o processo que eles estão vivendo e possam ajudar da melhor maneira possível.

Com este trabalho vimos que a criança é afetada por fatos que acontecem com as pessoas ao seu redor. Elas têm piores atitudes em relação à velhice quando idosos com quem moram possuem alterações cognitivas.

Diante disso, a criança deve ser inserida no plano de cuidado aos idosos, para que ela entenda as doenças do mesmo e saiba como ajudar, sem que seja necessário omitir informações.

Outras ações como grupos intergeracionais no âmbito do PSF podem ser importantes para uma integração das

\section{REFERÊNCIAS}

1. Brasil. Constituição, 1988. Constituição da República Federativa do Brasil. Brasília: Senado Federal; 1988.

2. Camarano AA, organizadora. Os novos idosos brasileiros: muito além dos 60? Rio de Janeiro: IPEA; 2004.

3. Camarano AA, El Ghaouri SK. Famílias com idosos: ninhos vazios? Rio de Janeiro: IPEA; 2003.

4. Neri AL. Palavras-chave em gerontologia. Campinas: Alínea; 2008.

5. Neri AL. Atitudes em relação à velhice: questões científicas e políticas. In: Freitas EV, Py L, Cançado FAX, Doll J, Gorzoni ML, organizadores. Tratado de geriatria e gerontologia. 2a ed. Rio de Janeiro: Guanabara Koogan; 2006. p.1316-23.

6. Rodrigues A, Assmar EML, Jablonski B. Psicologia social. 21a ed. Petrópolis: Vozes; 1999.

7. Neri AL. Atitudes e crenças sobre velhice: análise de conteúdo de textos do jornal O Estado de São Paulo publicados entre 1995 e 2002. In: Simon ORMV, Neri AL, Cachioni M, organizadores. As múltiplas faces da velhice no Brasil. Campinas: Alínea; 2003. p.13-54.

8. Cachioni M. Quem educa os idosos? Um estudo sobre professores de Universidades da Terceira Idade. Campinas: Alínea; 2003.

9. Osgood CE, Suci GJ, Tannenbaum PH. The measurement of meaning. New York: Appleton; 1957.

10. Tuckman J, Lorge I. Attitudes toward old people. J Soc Psychol. 1953;87(2):249-60.

11. Neri AL. Envelhecer num país de jovens: significados de veIho e velhice segundo brasileiros não idosos. Campinas: UNICAMP; 1991.

12. Neri AL. Atitudes em relação à velhice: evidências de pesquisa no Brasil. Gerontologia. 1997;5(3):130-9. gerações e troca de experiências. É dever dos profissionais de saúde incentivar e fazer parcerias com entidades que estão na área de abrangência das Unidades, como escola e centros comunitários, realizando ações que envolvam educação gerontológica, intergeracionalidade e que de alguma forma ajudem as crianças a compreender melhor o processo de envelhecimento.

Além disso, a formação de profissionais de saúde deve se voltar para a gerontologia devido ao crescimento do número de idosos na população e das doenças que acometem os mesmos. A importância da família e das crianças neste contexto também deve ser alvo de cursos que formam profissionais que lidam com as mesmas.

Pesquisas nesta área são importantes, pois as crianças de hoje serão os idosos se amanhã.

13. Neri AL, Jorge MD. Atitudes e conhecimentos em relação à velhice em estudantes de graduação em educação e em saúde: subsídios ao planejamento curricular. Estud Psicol. [Internet]. 2006 [citado 2010 jan. 11];23(2):127-37. Disponível em: http://www.scielo.br/pdf/estpsi/v23n2/v23n2a03.pdf

14. Burke JL. Young children's attitudes and perceptions of older adults. Int J Aging Hum Dev. 1981-1982;14(3):205-22.

15. Todaro MA. Desenvolvimento e avaliação de um programa de leitura visando à mudança de atitudes de crianças em relação a idosos [tese doutorado]. Campinas: Faculdade de Educação, Universidade Estadual de Campinas; 2008.

16. Folstein MF, Folstein SE, McHugh PR. Mini-Mental State: a practical method for grading the cognitive state of patients for the clinician. J Psych Res. 1975;12(3):189-98.

17. Bertolucci PHF, Brucki SMD, Campacci SR, Juliano Y. O Mini-Exame do Estado Mental em uma população geral: impacto da escolaridade. Arq Neuropsiquiatr. 1994;52(1):1-7.

18. Saad PM. Transferencias informales de apoyo de los adultos mayores en América Latina y el Caribe: estudio comparativo de encuestas SABE. Notas Población. 2003;3(77):175-217.

19. Instituto Brasileiro de Geografia e Estatística (IBGE). Informação do perfil dos idosos responsáveis pelos domicílios no Brasil, 2000. Rio de Janeiro; 2002.

20. Instituto Brasileiro de Geografia e Estatística (IBGE). Pesquisa Nacional por Amostra de Domicílios: síntese de indicadores, 2008. Rio de Janeiro; 2009.

21. Oliveira JCA, Tavares DMS. Elderly attention to Health Strategy in the Family: action of nurses. Rev Esc Enferm USP [Internet]. 2010 [cited 2010 Oct 19]; 44(3):774-81. Available from: http://www.scielo.br/pdf/reeusp/v44n3/en_32.pdf

\section{Agradecimentos}

Agradecemos à Fundação de Amparo à Pesquisa do Estado de São Paulo pelo apoio financeiro. 